\title{
Attenuating obscenity of swearwords in the amateur subtitling of English movies into
}

Arabic

\begin{abstract}
The interlingual subtitling of swearwords poses problems to translators due to differences in the degree of tolerating the obscenity of such words by various speech communities. To account for the perplexities incurred in the intercultural transference of swearwords, translators adopt attenuation strategies that facilitate their mediating role between cultures. In line with this, the present study attempts to identify the strategies adopted by Arab amateur subtitlers to mitigate the obscenity of swearwords in English movies. It utilizes a corpusbased approach to identify the factors affecting the decisions made by these subtitlers. The content analysis method was used in categorizing swearwords and in the translation comparison process, Toury's (1996) 'coupled pairs' model was adopted to identify attenuation strategies. The findings revealed that the common strategies used to mitigate the obscenity of swearwords are deletion, change of semantic fields, register shift and the use of archaic words, using euphemistic expressions, generalization and linguistic substitution and ambiguity. Moreover, cultural norms play a significant role in choosing the translation strategy to handle swearwords.
\end{abstract}

Keyword: Amateur subtitling; Attenuation; Swearwords; Translation behavior 
